\title{
TRICUSPID INCOMPETENCE AND RIGHT VENTRICULAR OUTPUT IN CONGESTIVE HEART FAILURE
}

\author{
BY \\ PAUL KORNER* AND JOHN SHILLINGFORD $\dagger$ \\ From the Department of Medicine, Postgraduate Medical School, Hammersmith \\ Received November_-15, 1955
}

Studies of the right atrial pressure and flow curves in patients with cardiac failure show that with a venous pressure of more than $8 \mathrm{~mm} . \mathrm{Hg}$, increasing amounts of functional tricuspid regurgitation may occur (Muller and Shillingford, 1954; Korner and Shillingford, 1954). If the forward flow is maintained, backflow through the valve will add a variable amount to the right ventricular stroke volume. Until recently the amount of increased stroke volume caused by valvular incompetence could only be inferred from right atrial pressure curves and necropsy observations. With the development of the dye dilution technique for the quantitative estimation of regurgitant flow (Korner and Shillingford, 1955) it has now been possible to gain further knowledge of the effect of valvular incompetence on the cardiac output and its relation to heart failure.

The purpose of this paper is to correlate the quantitative estimates of valvular regurgitation with the clinical and necropsy findings in a group of patients with tricuspid incompetence and to discuss these results in relation to the performance of the right ventricle in congestive heart failure.

\section{METHODS}

Fourteen patients were studied; ten had rheumatic heart disease, two hypertensive heart disease, one cor pulmonale, and one amyloid disease of the heart. In all the jugular venous pressure was raised to above a mean of $10 \mathrm{~mm}$. $\mathrm{Hg}$ measured from a reference point $5 \mathrm{~cm}$. below the sternal angle. The phlebograms all showed evidence of a positive systolic wave with obliteration of the $X$ descent. Cardiac catheterization was carried out in six patients using a Statham strain gauge with a direct current amplifier for the measurement of intracardiac pressures; the mean right atrial pressure in these patients varied between 11 and $26 \mathrm{~mm}$. $\mathrm{Hg}$ and the tracings all showed a positive systolic pulsation. Dye dilution curves were made in all cases by the technique previously described (Korner and Shillingford, 1955).

Routine examination was made on the hearts of six patients who came to necropsy; in three patients additional information was obtained by inserting a tube into the right ventricle via the cut pulmonary artery and perfusing water through the tricuspid valve with the whole heart under water. The behaviour of the valve leaflets and the aperture of reflux were then observed and photographed through the opened right atrium. Twenty control hearts from patients without evidence of heart disease were subjected to this test at autopsy.

\section{RESULTS}

The typical dye dilution curves obtained from a control subject and a patient with valvular incompetence are shown in Fig. 1. The effect of added valvular incompetence for a given cardiac output and volume between the point of injection and sampling site is to shorten the appearance time, decrease the maximum concentration, and prolong the rate of fall of the descending limb of the curve. The actual regurgitant flow was computed from the change in the shape of the curve.

Fig. 2 shows the total right ventricular output and the amounts of regurgitant flow and forward

* Research done during tenure of an Australian and New Zealand Life Insurance Medical Research Fellowship. $\dagger$ Member of the Medical Research Council Scientific Staff. 


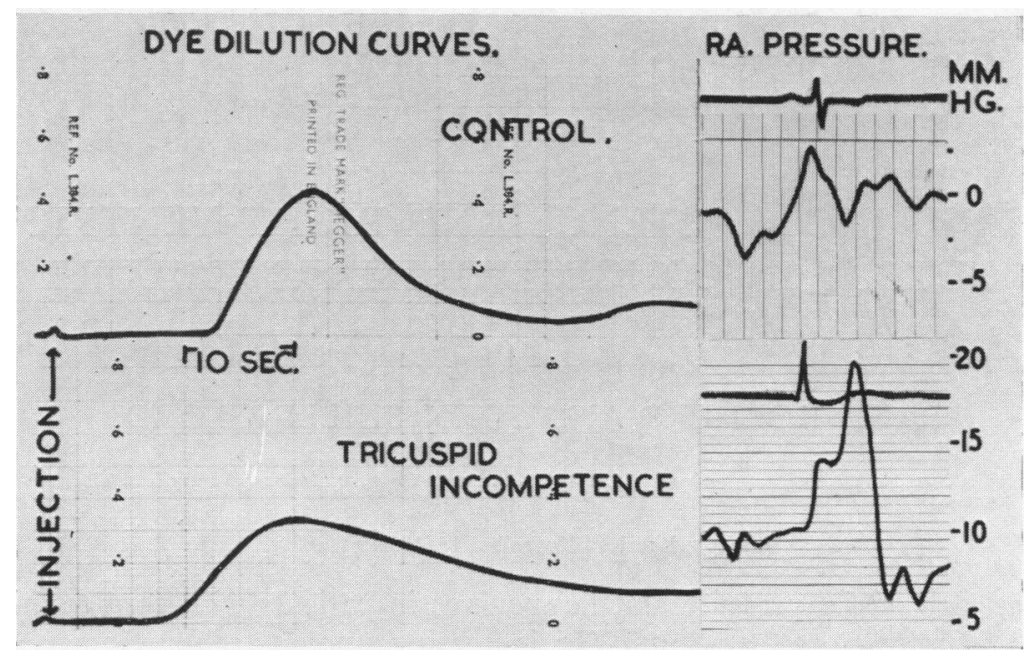

FIG. 1.-Dye dilution curves from a patient without valvular incompetence (above) and from one with tricuspid regurgitation (below). Corresponding right atrial pressure curves are shown alongside.

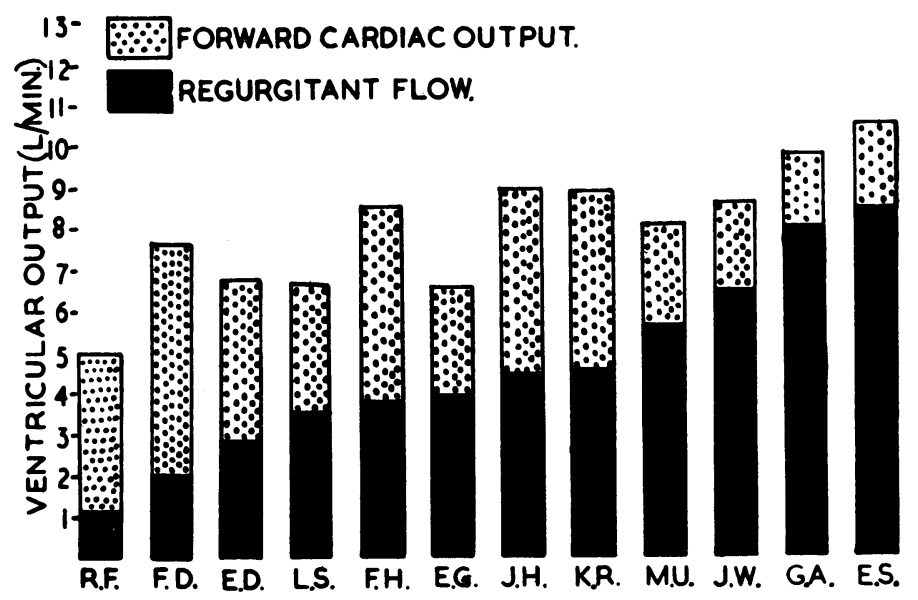

Fig. 2.-Total right ventricular output, showing the proportion of forward and regurgitant flows in twelve patients in congestive cardiac failure with tricuspid incompetence.

output in litres a minute in twelve of the patients, all of whom were in varying degrees of heart failure. The black columns represent the regurgitant flow from the right ventricle which varied between 1.2 and 8.2 litres a minute. The dotted columns represent the forward cardiac output from the right ventricle which varied between 5 and $2 \cdot 1$ litres a minute. The total right ventricular output, being the sum of regurgitant and forward flow, varied between $5 \cdot 2$ and 10 litres a minute. Although these patients were in congestive failure with, in most cases, a low forward cardiac output, the right ventricular output remained comparatively high and did not fall below $5 \cdot 2$ litres a minute. The average right ventricular stroke output was about $100 \mathrm{ml}$. and varied between 74 and $173 \mathrm{ml}$. As the regurgitant flow increased the forward flow tended to decrease and in cases where the latter was as low as $2 \cdot 1$ litres a minute the backflow reached about 8 litres a minute. 
The Effect of Rest and Exercise. The effect of exercise and rest in two patients with congestive heart failure was studied. Both had theumatic heart disease with mitral stenosis. Fig. 3 shows the change in the distribution of right ventricular output on rest and exercise in these patients. In the first (K.F.) the venous pressure, cardiac output, and regurgitant flow were measured when the

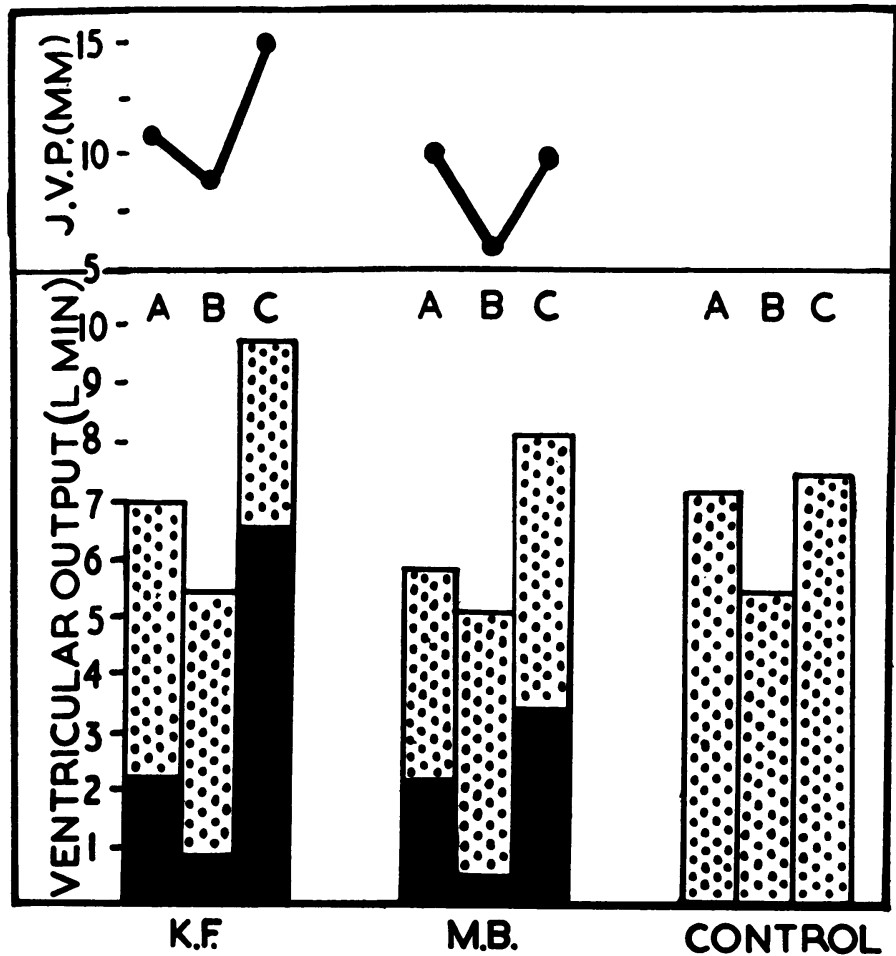

FIG. 3.-The effect of rest and exercise on the right ventricular forward and regurgitant flows on two patients compared with a subject not in cardiac failure. (A) Output soon after patient was placed on examination couch. two minutes mild exercise.

(B) After 20 minutes rest. (C) After

patient was first placed on the examining couch. The mean jugular venous pressure was $11 \mathrm{~mm}$., the forward cardiac output was 4.8 litres a minute, and the regurgitant flow 2.2 litres a minute, with a total right ventricular output of 7 litres a minute. After the patient had rested quietly for twenty minutes the venous pressure had fallen to $8 \mathrm{~mm}$., the forward cardiac output was 4.5 , and the regurgitant flow was 0.9 , with a total right ventricular output of 5.4 litres a minute. After two minutes exercise by gentle movement of the legs, the venous pressure rose to $15 \mathrm{~mm}$., the forward cardiac output fell to 3.2 , and the regurgitant flow rose to 6.7 litres a minute. It will be noted that the forward output actually fell on exercise, although the total right ventricular output rose considerably.

The second (M.B.) on the first test showed a mean jugular venous pressure of $10 \mathrm{~mm} . \mathrm{Hg}, \mathrm{a}$ forward cardiac output of $3 \cdot 7$, a regurgitant flow of $2 \cdot 1$, and a total right ventricular output of 5.8 litres a minute. After the patient had rested quietly for twenty minutes further observations showed that the forward cardiac output had risen to $4 \cdot 5$, and the regurgitant flow was 0.5 , with a total right ventricular output of 5 litres a minute. After two minutes gentle exercise the forward cardiac output was $4 \cdot 6$, the regurgitant flow $3 \cdot 5$, and the total right ventricular output $8 \cdot 1$ litres a 
minute. In this case exercise did not significantly change the forward cardiac output although the right ventricular output was greatly increased.

Clinical Observations. The typical murmur of tricuspid incompetence (Muller and Shillingford, 1954) was heard in all cases (Fig. 4) but no correlation between the intensity of the murmur and the volume of backflow was attempted in this study. Three of the patients with an abnormally
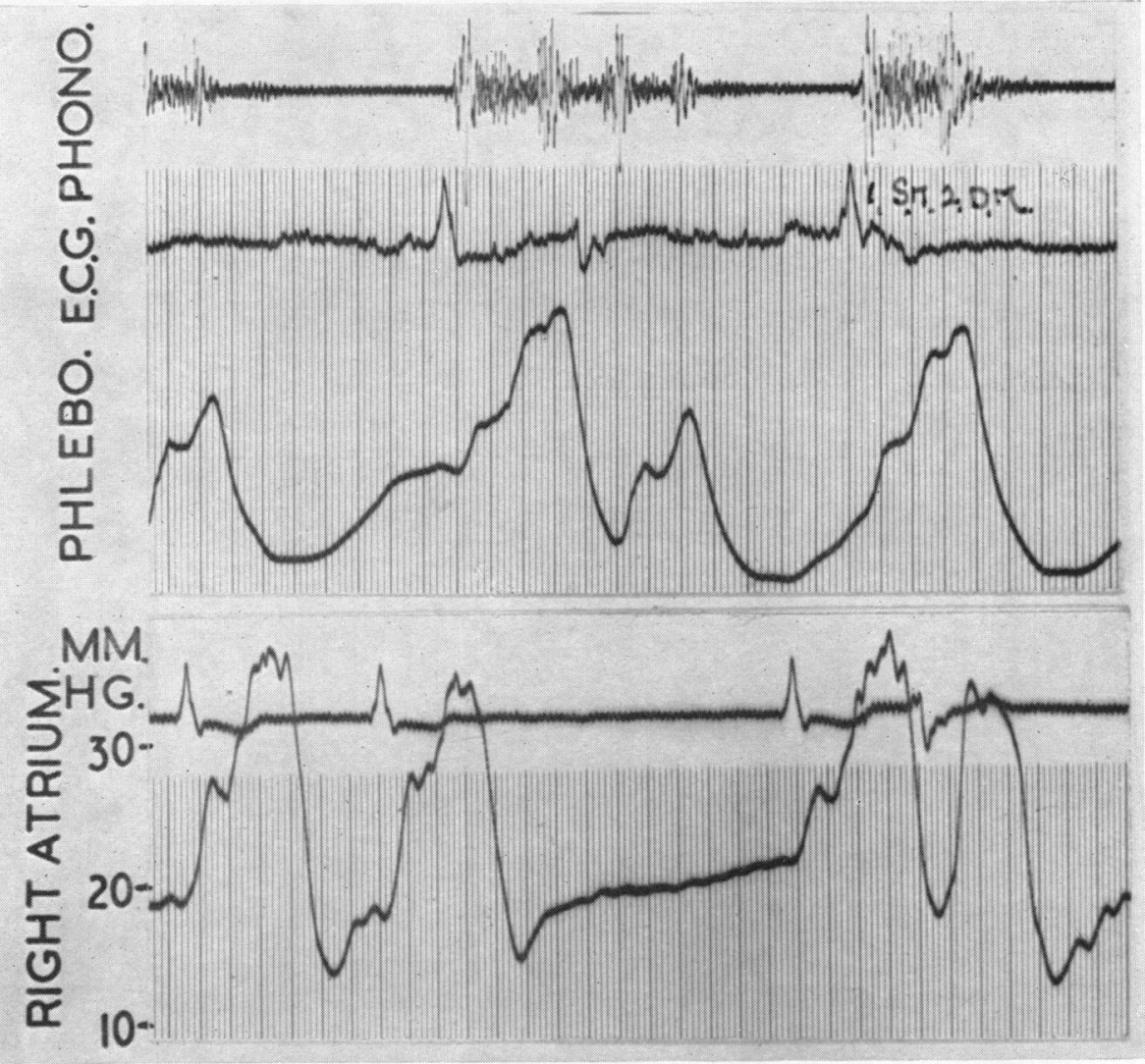

Fig. 4.-Phonocardiogram, phlebogram, and right atrial pressure pulse from patient J. H. (see text).

low forward cardiac output showed great right ventricular pulsation; this could be explained on the high right ventricular stroke output due to the addition of the tricuspid regurgitation. Systolic expansion of the liver appeared to be the physical sign most closely correlated with the volume of regurgitant flow; in no case where the regurgitant flow was below 3.5 litres a minute was there general agreement that liver pulsation could be felt; with backflows above this figure liver pulsation was palpable in the majority of patients. It is not difficult to appreciate that a regurgitant stroke output of 40 to $50 \mathrm{ml}$. or less could be readily taken up in the right atrium and great veins and not be readily felt as pulsation of the liver.

There was no simple relationship between the amount of regurgitant flow and the venous pressure. Fig. 5 shows the right atrial pressure plotted against regurgitant flow in litres a minute and also against right ventricular stroke output in six patients where accurate measurement of the right atrial pulse pressure was made at cardiac catheterization. The lack of relationship is not surprising as the right atrial pressure is determined not only by the backflow but by the volume elasticity relationships of the venous system. Other factors of importance in the elevation of the 


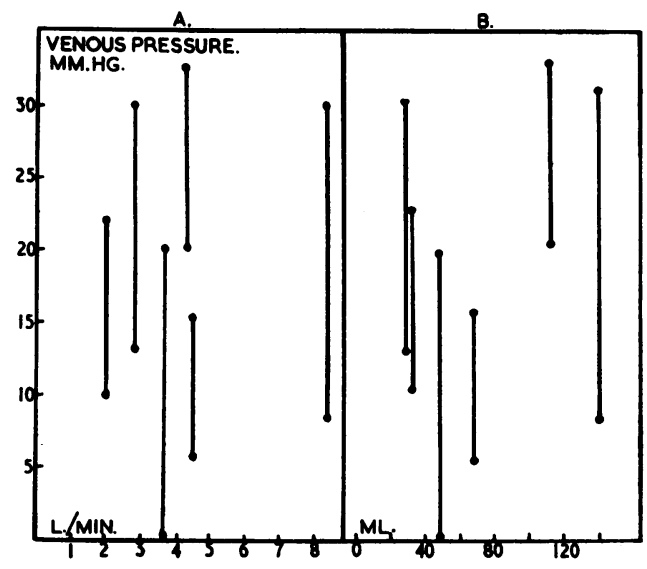

FIG. 5.-Relation of venous pressure (systolic and end-diastolic) to backflow. ((A) litres/min.; (B) $\mathrm{ml}$./beat) in six cases of tricuspid incompetence.

central venous pressure probably include blood volume expansion, venous constriction, and increase in forward flow (Landis and Hortenstine, 1950). At the same time the relationship may not be the same in functional as in organic tricuspid incompetence.

A positive systolic wave of the jugular venous pulse was recorded in all the patients. When the pulse rate was slow, it was easy to recognize this pulsation by direct observation, but in cases with tachycardia and a corresponding lower stroke output the study of a jugular phlebogram was necessary to confirm the presence of a positive systolic wave.

Post-mortem Findings. Six patients came to necropsy; three of the hearts were studied in the routine way, while in the others the valves were perfused as previously described. A series of twenty control hearts showed the tricuspid valve to close competently to this test (Fig. 6B). Two of the cases subjected to this test showed organic disease of the valves with partial fusion of the cusps with an incompetent orifice of an average diameter of $2.5 \mathrm{~cm}$. in each case; the other case was one of amyloid disease with dilatation of the valve ring and an incompetent orifice of $2.0 \mathrm{~cm}$. diameter. All the cases were reported as showing dilatation of the right ventricular cavity and the tricuspid valve ring.

The pulmonary outflow tract and pulmonary valve from a normal heart are shown in Fig. 6A, with photographs of the tricuspid valve taken at the same magnification. It will be seen that the orifice of the incompetent tricuspid valve approached in size that of the pulmonary valve, adding further support to the hæmodynamic observations that the regurgitant flow may be as great or greater than the forward flow in patients with congestive heart failure and tricuspid incompetence. This regurgitant flow may be greater than the forward flow even if the orifices are of the same size, as in most cases the right atrial pressure is lower than the pulmonary arterial pressure.

Examples of two cases, one with organic and the other with functional tricuspid incompetence, are given below.

(1). Clerk, aged 36 years. Rheumatic fever at the age of 9 and 16; breathless on exertion after second attack. First seen at hospital at age of 32 with increasing breathlessness and upper abdominal discomfort. Slow auricular fibrillation. Jugular venous pressure $6 \mathrm{~cm}$. above sternal angle with positive systolic pulsation. Cardiac enlargement to the right of the sternum. Apex beat $15 \mathrm{~cm}$. to left of midline in the sixth interspace. Systolic and mid-diastolic murmurs at apex. Systolic murmur at aortic area and at lower end and to the right of the sternum. Liver enlarged three fingers' breadths with positive systolic pulsation. X-ray of heart showed enlargement of left atrium and right ventricle. E.C., right ventricular preponderance. Given digitalis with improvement. Last admission aged 36. Increasing congestive heart failure with œdema and ascites. Auscultation as before but with increase in the intensity of the tricuspid murmur and pulmonary second sound. Liver four fingers' breadths below costal margin with systolic pulsation. Right atrial pressure $35 / 20$ (mean 26) mm. Hg. Total right ventricular output 8.9 litres a minute (forward fiow, $4 \cdot 5$ litres a minute; regurgitant flow, $4 \cdot 4$ litres a minute). 

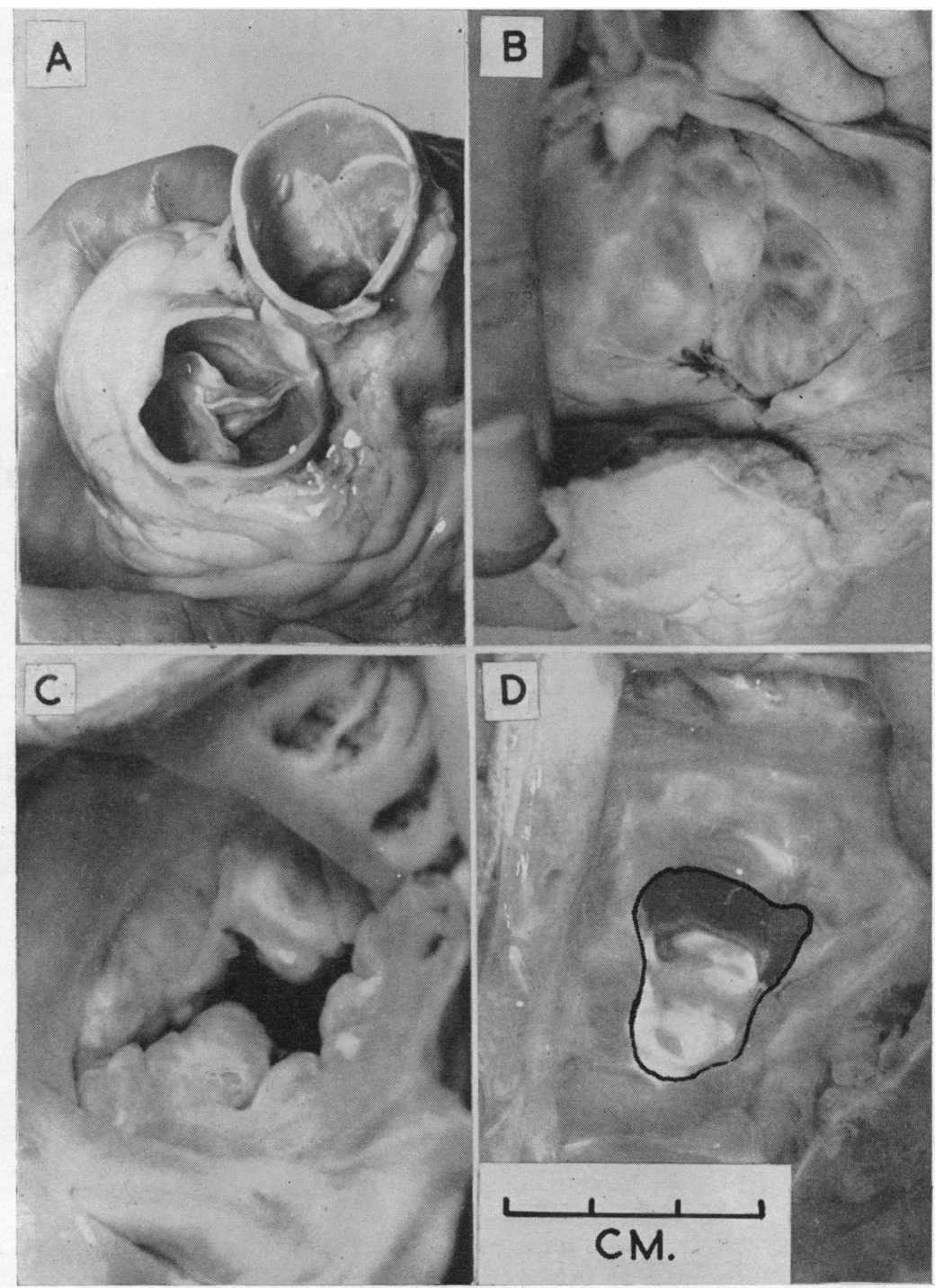

Fig. 6.-Necropsy photographs of the tricuspid valves during retrograde perfusion of the right ventricle. (A) Normal pulmonary valve. (B) Normal tricuspid valve. (C) Functional incompetence in a case of amyloid heart disease. Forward output $2 \cdot 8$, regurgitant flow $3 \cdot 8$ litres a minute. (D) Organic incompetence following fusion of the valves in a case of rheumatic heart disease. Forward output 4.5 , regurgitant flow 4.4 litres a minute.

Necropsy. Heart 770 g. Left ventricle moderate hypertrophy and dilatation. Left atrium great dilatation and hypertrophy. Right ventricle great hypertrophy and dilatation. Mitral valve; buttonhole stenosis admitting the tip of the index finger; chordæ tendineæ shortened, thickened, and fibrosed with calcified edges. Aortic valve, slight fusion of valve cusps. Tricuspid valve, fusion of cusps combined with dilatation of valve ring giving an incompetent orifice of $2.5 \mathrm{~cm}$. diameter.

(2). Housewife, aged 56 years. Fifteen months chest pain on exertion, increasing breathlessness; six months discomfort in upper abdomen, occasional vomiting; six weeks œdema of legs and increasing dyspnœa.

O.E. Orthopnœa, œedema of legs and sacrum. Jugular venous pressure $10 \mathrm{~cm}$. above sternal angle with positive systolic wave. Pulse rate 120 a minute, regular; B.P. 130/80. Apex beat in anterior axillary line in sixth interspace. Triple rhythm at apex and systolic murmur at lower end and to the right of the 
sternum. Small right pleural effusion. Liver four fingers' breadths below costal margin, firm and smooth. X-ray of heart, moderate enlargement with prominent pulmonary artery. Pulmonary artery pressure, 40/28; right ventricular pressure, 40/5; right atrial pressure $30 / 15 \mathrm{~mm}$. Hg. Total right ventricular output 6.6 litres a minute (forward flow $2 \cdot 8$, and regurgitant flow 3.8 litres a minute).

Necropsy. Heart $495 \mathrm{~g}$. Moderate hypertrophy and dilatation of right atrium and right ventricle. Dilatation and resultant incompetence of tricuspid valve with incompetent orifice about $2.0 \mathrm{~cm}$. diameter. Left ventricle hypertrophied, but not dilated. No coronary artery narrowing. Myocardium hypertrophied, pale, and glassy, with firm cut edge; strongly positive for amyloid reaction.

\section{Discussion}

Previous work has shown that in congestive heart failure a grossly raised venous pressure is usually accompanied by functional tricuspid regurgitation. The development of the dye dilution method (Korner and Shillingford, 1955) has enabled a quantitative estimate of the amount of regurgitation to be made. The results show that the average total right ventricular output at rest in patients with congestive heart failure and tricuspid incompetence is about 50 per cent higher than in normal resting subjects. There appeared to be an inverse relationship between the forward output and regurgitant flow, so that when the forward output was abnormally low the regurgitant flow was high. In the group studied, although the forward and regurgitant flow varied within wide limits between the patients, the total right ventricular output was relatively fixed. The effect of mild exercise on such patients was to increase the total ventricular output slightly, although the forward cardiac output might remain the same or even fall at the expense of increased regurgitant flow. This correlates with previous work where exercise has been shown to increase the mean right atrial pressure, the right atrial pulse pressure, the intensity of the systolic murmur, and the backflow in the atrium as measured by differential manometry (Muller and Shillingford, 1954; 1955). This alteration in the distribution of blood flow may help to explain the phenomenon of "fixed cardiac output" seen in cases of mitral stenosis and heart failure (Hickam and Cargill, 1948; Donald et al., 1954).

The regurgitant backflow is regulated not only by the relative sizes of the orifices of the incompetent tricuspid valve and pulmonary outflow tract, but also by the pressure gradients between the right atrium, right ventricle, and pulmonary artery. For example, in one patient with functional tricuspid incompetence, where the regurgitant flow was a little less than the forward flow and the mean pulmonary arterial pressure twice that of the mean right atrial pressure, the diameter of the perfused incompetent valve at necropsy was about half that of the pulmonary outflow tract.

While exercise reduced the efficiency of right ventricular performance owing to the increased backflow, our results perhaps indicate that the improvement following rest and possibly venesection or digitalis (McMichael, 1950) could be the result of a diminution in the regurgitant flow.

\section{SUMMARY}

Quantitative estimates of the amount of backflow through incompetent tricuspid valves have been correlated with the clinical and necropsy findings in fourteen patients in congestive failure.

When functional tricuspid incompetence develops in congestive failure the right ventricular output remains high in spite of a low forward cardiac output, because of the large regurgitant flow.

Exercise may increase the regurgitant flow at the expense of forward cardiac output. Rest has the opposite effect.

The regurgitant flow is thought to be important in maintaining a low fixed forward cardiac output in some cases of congestive cardiac failure.

\section{REFERENCES}

Donald, K. W., Bishop, J. M., and Wade, O. L. (1954). J. Clin. Invest., 33, 1146.

Hickham, J. B., and Cargill, W. H (1948). J. Clin. Invest., 27, 10.

Korner, P., and Shillingford, J. (1954). Brit. Heart. J., 16, 447. (1955). Clin. Sci., 14, 553.

Landis, E. M., and Hortenstine, J. C. (1950). Physiol. Revs., 30, 1.

McMichael, J. (1950). The Pharmacology of the Failing Human Heart. London, Blackwell.

Muller, O., and Shillingford, J. (1954). Brit. Heart J., 16, 195.

(1955). Brit. Heart J., 17, 163. 